\title{
An Interconnected Hierarchical Porous Carbon Material Prepared by Polymer Precursor and Its Application as Electrode in Supercapacitors
}

\author{
Fen Ran ${ }^{1,2, a}{ }^{*}$, Yong-Tao Tan ${ }^{1,2}$, Ling-Bin Kong ${ }^{1,2}$, Long Kang ${ }^{1,2}$ \\ ${ }^{1}$ State Key Laboratory of Gansu Advanced Non-Ferrous Metal Materials, Lanzhou University of \\ Technology, Lanzhou 730050, P. R. China \\ ${ }^{2}$ Key Laboratory of Non-ferrous Metal Alloys and Processing of Ministry of Education, Lanzhou \\ University of Technology, Lanzhou 730050, P. R. China \\ *Corresponding author. Tel.: +86 9312976579 ; Fax: +86 9312976578. \\ âE-mail address: ranfen@163.com
}

Keywords: Interconnected Hierarchical Porous Carbon; High Internal Phase Emulsion (HIPE); Supercapacitors;

Abstract. Interconnected hierarchical porous carbon (IHPC) was prepared by a poly(high internal phase emulsion) (polyHIPE) and carbonation method based on phenolic-formaldehyde resin for supercapacitors. Structural and morphological characterizations of IHPC were carried out using field emission scanning electron microscopy (SEM). Capacitive behaviors of IHPC were investigated by cyclic voltammetry and galvanostatic charge-discharge. Electrochemical tests showed IHPC material have a maximum capacitance of $106 \mathrm{~F} / \mathrm{g}$ and good cycle stability for supercapacitor application.

\section{Introduction}

Energy is one of the most important topics in the 21 st century. With the rapid depletion of fossil fuels and increasingly worsened environmental pollution caused by vast fossil-fuel consumption, there is high demand to make efficient use of energy and to seek renewable and clean energy sources that can substitute fossil fuels to enable the sustainable development of our economy and society. Energy storage, an intermediate step to the versatile, clean, and efficient use of energy, has received worldwide concern and increasing research interest [1].

Electrochemical capacitors (ECs), as the intermediate devices between conventional batteries and dielectric capacitors, have drawn increasingly attention because of its safety, short charging time and electrochemical stability [2]. It is well known that electrode material is one of the dominating factors that influence the performance of the ECs [3,4]. At present, three different types of supercapacitors are commonly described in literature, depending on the nature of the active material used, carbon materials [5-7], conducting polymers [8-10], and metal-oxides [11-13]. Carbon materials are useful in wide application due to its good conductivity, low cost, and high surface area. Moreover, the carbon materials have good power density, good stability and low resistance for supercapacitors. Carbon materials involved activated carbon [14,15], carbon fiber [16,17], carbon nanotubes [18], and porous carbon [19,20], et al.

In this paper, an interconnected hierarchical porous carbon (IHPC) was prepared by the polyHIPE and carbonation method based on phenolic-formaldehyde resin for supercapacitors. Structural and morphological characterizations of IHPC were carried out using field emission scanning electron microscopy (SEM), Capacitive behavior of IHPC was investigated by cyclic voltammetry and galvanostatic charge-discharge in $2 \mathrm{M} \mathrm{KOH}$ aqueous solution. The maximum capacitance was up to $106 \mathrm{~F} / \mathrm{g}$ at the density of $5 \mathrm{~mA} / \mathrm{cm}^{2}$.

\section{Experiments}

All of the chemicals were analytical grade, purchased from Sinopharm Chemical Reagent Co. Ltd. and used without further purification. 
Synthesis of porous polymeric material: Resorcinol and formalin $\left(\mathrm{n}_{\mathrm{resorcinol}}: \mathrm{n}_{\text {formalin }}=1: 2\right)$ were added to a container and heated to $30^{\circ} \mathrm{C}$ to form a homogeneous solution. After cooling to room temperature a certain mass of amphoteric emulsifier sodium dodecylsulfate (SDS) was added. The resulting clear solution was stirred with a paddle stirrer while a certain volume ratio of droplet phase cyclohexane was added dropwise over a period of 30 minutes to form a thick HIPE. An acidic catalyst, phosphoric acid $(50 \%, 3 \mathrm{~g})$ was then stirred into the emulsion. A rigid polymer was formed after heating at $60{ }^{\circ} \mathrm{C}$ for 10 minutes and further dried at $75^{\circ} \mathrm{C}$ for $24 \mathrm{~h}$ in a vacuum oven.

Preparation of IHPC: The phenolic-formaldehyde polymer held at $60^{\circ} \mathrm{C}$ for $2 \mathrm{~h}$ and then was cured by slowly ramping to desired curing temperature from $60{ }^{\circ} \mathrm{C}$. In general, it was indispensable that heating rate at stages of curing was less than $2{ }^{\circ} \mathrm{C} / \mathrm{h}$ in order to avoid the appearance of cracks in the carbon. The temperature was increased to $160^{\circ} \mathrm{C}$ and kept it for $24 \mathrm{~h}$. The sample after curing was named as cured body. At last, the cured body was pyrolyzed by slowly ramping to $900{ }^{\circ} \mathrm{C}$ in a flowing nitrogen atmosphere, followed by cooling naturally to room temperature. The products were characterized by using SEM (Model JSM-6701F, Japan).

Electrode preparation: A total of $80 w t . \%$ of electroactive material powder was mixed with 7.5 $w t . \%$ of acetylene black (>99.9\%) and $7.5 w t . \%$ of conducting graphite in an agate mortar until a homogeneous black powder was obtained. To this mixture, 5 wt. \% of poly (tetrafluoroethylene) was added with a few drops of ethanol. After briefly allowing the solvent to evaporate, the resulting paste was pressed at $10 \mathrm{M}$ Pa to nickel foam current collector for an electric connection. The electrode assembly was dried for $12 \mathrm{~h}$ at $60{ }^{\circ} \mathrm{C}$ in air. Each electrode contained about $8 \mathrm{mg}$ of electroactive material and had a geometric surface area of about $1 \mathrm{~cm}^{2}$.

Electrochemical tests: Electrochemical measurements were carried out using an electrochemical working station (CHI660C, Shanghai, China) in a half-cell setup configuration at room temperature. A platinum gauze electrode and a saturated calomel electrode (SCE) served as the counter electrode and the reference electrode, respectively. Cyclic voltammetry (CV) scans were recorded from -1.0 to $0 \mathrm{~V}$ at different scan rate and charge-discharge cycle tests were carried out in the potential range from -1.0 to $0 \mathrm{~V}$ at different current density in $2 \mathrm{M} \mathrm{KOH}$ aqueous solution. All electrochemical experiments were carried out at $20 \pm 1{ }^{\circ} \mathrm{C}$.

\section{Results and discussion}

Preparation and characterization of IHPC
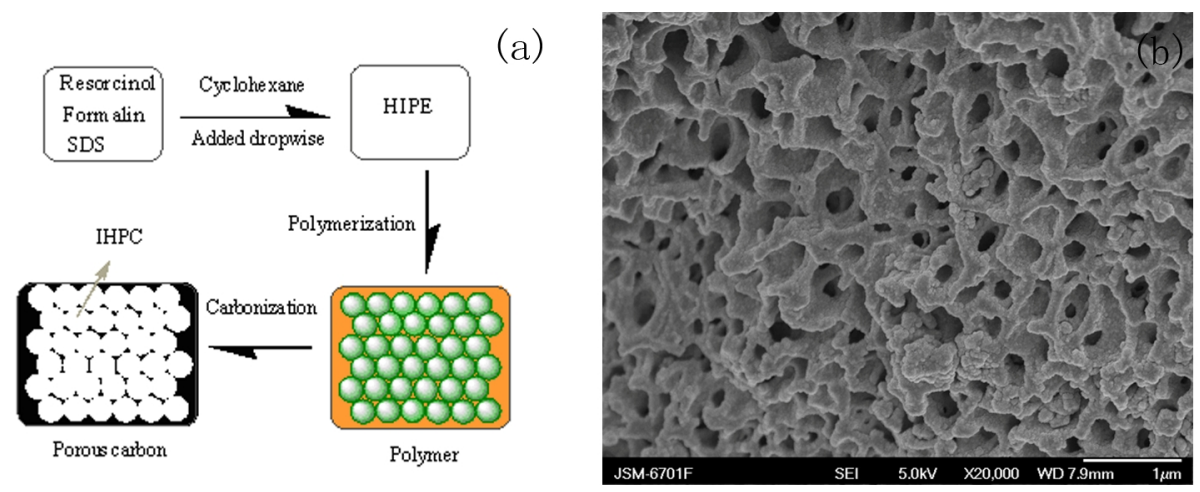

Fig.1 Mechanism for the preparation of IHPC (a) and SEM image of IHPC (b)

The mechanism for the preparation of interconnected porous carbon was summarized as follows (as shown in Fig. 1a ): Two monomers plus suitable surfactant were mixed together while the droplet phase liquid (cyclohexane) was added dropwise. The droplet phase was to break up large droplet due to the paddle stirrer. When droplet phase was up, the stable emulsion formed and was called high internal phase emulsion (HIPE). Then, polymerization of the continuous phase of a concentrated emulsion followed by removal of the internal phase leads to the formation of emulsion-templated interconnected porous polymer. Finally, the resulting polymeric material was further pyrolyzed at 900 ${ }^{\circ} \mathrm{C}$ under nitrogen atmosphere condition to obtain IHPC. Fig. 1b shows SEM image of IHPC with 
volume fraction of dispersed phase of $80 \%$ and $0.8 \mathrm{~g}$ SDS. From Fig. 1b, it is clear to see that the prepared IHPC is a highly porous cross-linked carbon material having cell sizes within the range 50 to $200 \mathrm{~nm}$ and shows a three-dimensional (3D) network.

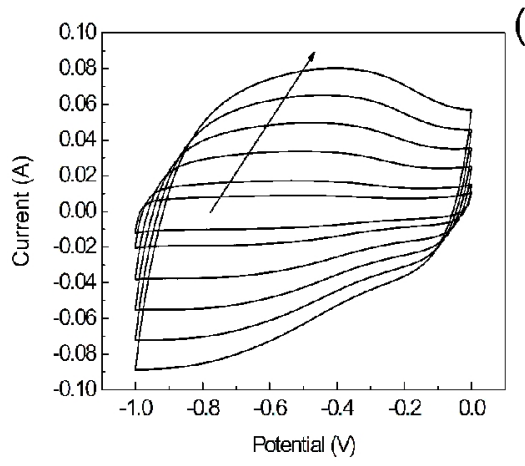

(a)

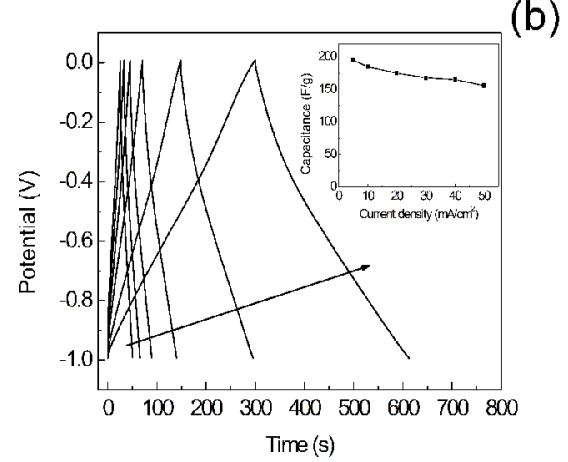

Fig.2 (a) Cyclic Voltammetry of IHPC at different scan rates (arrow indicating the direction of increasing scan rates from 5, 10, 20, 30, 40,50 mV/s); (b) Galvanostatic charge-discharge behavior of IHPC at different current densities (arrow indicating the direction of decreasing current density from 50, 40, 30, 20, 10, to 5 $\mathbf{m A} / \mathrm{cm}^{2}$ ), the inset is the relationship between capacitance and current density

Electrochemical performance of IHPC: Fig. 2(a) represents the cyclic voltammetry behavior of IHPC electrode in $2 \mathrm{M} \mathrm{KOH}$ aqueous solution. The typical rectangle-like shape of all $\mathrm{CV}$ curves measured at various scan rates reveals the electrochemical capacitive behavior of IHPC electrode. The curves at different scan rates show no obvious peaks. With the scan rate increasing, cyclic voltammetry curves (CVs) of IHPC retain a similar shape even at high scan rate, indicating that IHPC possess high conductivity. Galvanostatic constant current charge/discharge measurements at different current densities were applied to evaluate the electrochemical properties and to quantify the capacitance of IHPC electrode. Fig. 2(b) shows the typical galvanostatic charge-discharge curves of IHPC electrode between -1.0 and $0 \mathrm{~V}$ at different current densities. The capacitances of the IHPC at 5, 10, 20, 30, 40 and $50 \mathrm{~mA} / \mathrm{cm}^{2}$ were $106,96,90,82,80$ and $75 \mathrm{~F} / \mathrm{g}$, respectively. It can be reached nearly $71 \%$ of the initial amount under high current density of $50 \mathrm{~mA} / \mathrm{cm}^{2}$.

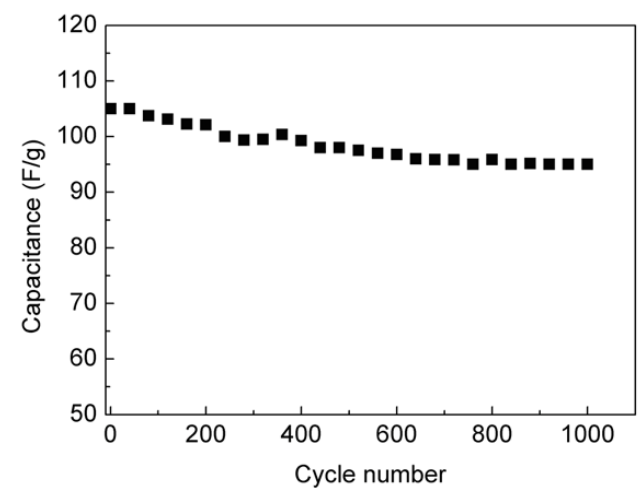

Fig. 3 Cycle life data of IHPC electrode at a discharge current of $5 \mathrm{~mA} / \mathrm{cm}^{2}$

The cyclic stability of IHPC: The cyclic stability of IHPC was observed by continuous charge-discharge cycling, as shown in Fig. 3 (cycle potential window: -1 to $0 \mathrm{~V}$ vs. SCE). After 1000 charge-discharge cycles, the capacitance of the IHPC decreased about $9 \%$. The result reveals that IHPC electrode enjoys high stability for long cyclic life.

\section{Conclusions}

1. IHPC for electrochemical supercapacitors was fabricated by a PolyHIPE and carbonation method based on phenolic-formaldehyde polymer.

2. The structure of IHPC was 3D network through the SEM images and the volume fraction of droplet phase and mass of emulsifier had a certain effect on capacitance of IHPC. 
3. Electrochemical tests showed the maximum capacitance was $106 \mathrm{~F} / \mathrm{g}$ at current density of 5 $\mathrm{mA} / \mathrm{cm}^{2}$ with mass of emulsifier of $0.8 \mathrm{~g}$ and appropriate volume fraction of droplet phase of $80 \%$.

4. After 1000 charge-discharge cycles, the capacitance of the IHPC decreased about $9 \%$ which shows a better stability.

\section{Acknowledgments}

This work was supported by the National Natural Science Foundation of China (51203071, 51363014 and 51362018), China Postdoctoral Science Foundation (2014M552509, 2015T81064), the Opening Project of State Key Laboratory of Polymer Materials Engineering (Sichuan University) (sklpme2014-4-25), the Program for Hongliu Distinguished Young Scholars in Lanzhou University of Technology (J201402), and the University Scientific Research Project of Gansu Province (2014B-025).

\section{References}

[1] Liu C, Li F, Ma LP, Cheng HM (2010) Adv Mater 22:E28-E62

[2] Kotz R, Carlen M (2000) Electrochim Acta 45:2483-2498

[3] Rios EC, Rosario AV, Mello RMQ, Micaroni L (2007) J Power Sources 163:1137-1142

[4] Wang B, Konstantinov K, Wexlera D, Liub H, Wang GX (2009) Electrochim Acta 54:1420-1425

[5] Gamby J, Taberna PL, Simon P, Fauvarque JF, Chesneau M (2001) J Power Sources 101:109-116

[6] Ruiz V, Blanco C, Santamaría R, Ramos-Fernández JM, Martínez-Escandell M, Sepúlveda-Escribano A, Rodríguez-Reinoso F (2009) Carbon 47:195-200

[7] Chen QL, Xue KH, Shen W, Tao FF, Yin SY, Xu W (2004) Electrochim Acta 49:4157-4161

[8] Subramania A, Devi SL (2008) Polym Adv Technol 19:725-727

[9] Wang LR, Ran F, Tan YT, Zhao L, Kong LB, Kang L (2011) Chin Chem Lett 22:964-968

[10] Ahmad S, Riaz U, Kashif M, Khan MS (2012) J Appl Polym Sci 1:365-372

[11]Qian Y, Lu SB, Gao FL (2011) J Mater Sci 46:3517-3522

[12]Lang JW, Kong LB, WJ Wu, Luo YC, Kang L (2008) Chem Commun 35:4213-4215

[13]Prasad KR, Miura N (2004) Electrochem Commun 6:1004-1008

[14] Kierzek K, Frackowiak E, Lota G, Gryglewicz G, Machnikowski (2004) J Electrochim Acta 49:515-523

[15]Barbieri O, Hahn M, Herzog A, Kotz R (2005) Carbon 43:1303-1310

[16] Kim C (2005) J Power Sources 142:382-388

[17] Nakagawa H, Shudo A, Miura K (2000) J Electrochem Soc 147:38-42

[18] Raymundo-Pinero E, Khomenko V, Frackowiak E, Beguin F (2005) J Electrochem Soc 152:A229-A235

[19]Su F, Zeng JH, Bao XY, Yu YS, Lee JY, Zhao XS (2005) Chem Mater 17:3960-3967

[20]Zhang JT, Gong LY, Sun K, Jiang JC, Zhang XG (2012) 16: 2179-2186 